\title{
Biological monitoring of occupational exposure to toluene diisocyanate: measurement of toluenediamine in hydrolysed urine and plasma by gas chromatography-mass spectrometry
}

\author{
Pernilla Persson, Marianne Dalene, Gunnar Skarping, Mikael Adamsson, Lars Hagmar
}

\begin{abstract}
Exposure to toluene diisocyanate (TDI) was studied during 48 hours and biological samples from nine subjects were taken in a factory producing flexible polyurethane (PUR) foam. Five PUR workers, two white collar workers, and two volunteers were studied. The concentrations of TDI in air were determined by high performance liquid chromatography with the 9-(N-methylaminomethyl)-anthracene reagent. Urine and plasma samples were collected and the TDI related amines, 2,4-toluenediamine $(2,4-$ TDA) and 2,6-toluenediamine (2,6-TDA), were determined (after hydrolysis) as pentafluoropropionic anhydride (PFPA) derivatives by capillary gas chromatography-mass spectrometry (GC-MS) with selected ion monitoring (SIM) in the negative chemical ionisation mode. The concentration of TDI in air was $1 \%-10 \%$ of the Swedish threshold limit value (TLV) of $40 \mu \mathrm{g} / \mathrm{m}^{3}$. The ratio between $2,4-T D I$ and 2,6-TDI varied in the air samples in the range of $60 \%: 40 \%-5 \%: 95 \%$. Calibration plots for human urine spiked with 2,6-TDA and 2,4TDA in the range of $0.2-12 \mu \mathrm{g} / 1$ were produced on eight different occasions during five weeks. The SDS of the calibration plot slopes $(n=8)$ were less than $4 \%$. Urine and blood samples were taken on six occasions for eight of the studied subjects and on four occasions for one subject during a two day period. The five male PUR workers showed the highest average urinary elimination rate of TDA. Two PUR workers and the two white collar workers had an elimination rate of $20-70 \mathrm{ng}$ on average for
\end{abstract}

Department of Occupational and Environmental Medicine, University Hospital S-221 85 Lund Sweden

P Persson, $M$ Dalene, G Skarping, M Adamsson, L Hagmar the sum of 2,6-TDA and 2,4-TDA per hour and three PUR workers had an average of 100-300 ng TDA per hour. The elimination rate curves for all the studied subjects had a linear relation with exposure to TDI.

The concentrations of 2,4-TDA and 2,6TDA in plasma for the PUR factory employees were virtually stable. No relation between the elimination rates of TDA in urine and plasma concentrations of TDA was found. The five PUR workers showed plasma concentrations of the sum of 2,4-TDA and 2,6-TDA in the range 1-8 $\mathrm{ng}$ per $\mathrm{ml}$. The two white collar workers, present only on occasions in the factory, had 0.2-1 ng TDA per ml plasma. The two volunteers showed an increasing concentration of TDA in plasma with time. At the end of the study their plasma concentrations were $0.6 \mathrm{ng} / \mathrm{ml}$ and $0.2 \mathrm{ng} / \mathrm{ml}$ plasma. Three subjects had the same concentration of the two TDA isomers in plasma, two subjects had about double, and two subjects had 12 times higher concentrations of 2,6-TDA than 2,4TDA. The presented study indicates that it is possible to monitor exposure to TDI by monitoring plasma concentrations of TDA.

(British Fournal of Industrial Medicine 1993;50:1111-1118)

Toluene diisocyanates (2,4-TDI and 2,6-TDI) are important industrial chemicals in the manufacture of polyurethane (PUR) foams, paints, coatings, and elastomers. ${ }^{1}$ They are commercially available as an isomer mixture containing $80: 20$ or $65: 35$ of 2,4-TDI and 2,6-TDI. A relative enrichment of the 2,6-isomer has been found in industrial atmospheres. ${ }^{2}$

Exposure to TDI may cause irritation of the mucous membranes and a progressive impairment of pulmonary function. ${ }^{3}$ It has sensitising properties and may cause allergic asthma. ${ }^{4}$ Further, commercial grade TDI is carcinogenic to animals. ${ }^{5}$ No increased overall incidence of cancer was, however, found among workers from the Swedish 
polyurethane foam manufacturing industry. ${ }^{6} \mathrm{~A}$ non-significant increased risk of non-Hodgkin's lymphoma and rectal cancer was found but it could not be conclusively associated with exposure to TDI. Kennedy and Brown have recently reviewed isocyanates found in the work environment and toxicity and illnesses caused, together with experimental approaches, biological mechanisms, and the formation of protein TDI adducts.?

Several methods for the determination of isocyanates in air have been described..$^{8-10}$ Detection limits for these methods are much lower than the threshold limit values. Short term exposure control is therefore possible. In Sweden a 5 minute TLV has been applied since 1984. Air monitoring, which is the present available method for assessing occupational exposure to TDI, has several disadvantages. In practice, measuring the air concentration of isocyanates with time during a workday requires many samples and is costly. Measuring random peak exposure is therefore not feasible in the work environment. Also the method does not take dermal absorption into consideration. This is a disadvantage regarding the potential risk of cancer and also asthma as it has been shown by Karol et al that dermally absorbed TDI may be responsible for pulmonary hypersensitivity to TDI. ${ }^{11}$

Diisocyanates are highly reactive with many compounds containing active hydrogen - for example, carboxyl and amino groups in proteins. ${ }^{12}{ }^{13} \mathrm{It}$ is therefore likely that TDI reacts with the tissue it initially reaches rather than being absorbed and distributed throughout the body as unchanged compounds. ${ }^{1}$ In an inhalation study carried out with radioactively labelled TDI in guinea pigs, ${ }^{14}$ the radioactivity in the blood seemed to be irreversibly attached to a specific plasma component, a protein with a molecular weight of $71000 \mathrm{Da}$; this finding indicates the possibility of an extremely specific interaction between proteins and TDI. Kennedy $e t$ al have shown that the rate of uptake of TDI into the blood of guinea pigs is linear during exposure. ${ }^{15}$ Rosenberg et al have studied exposure of workers to toluene diisocyanate monomer in a factory producing flexible polyurethane. ${ }^{16}$

The aim of our study was to develop a method for the biological monitoring of occupational exposure to TDI in urine and plasma samples from PUR workers.

\section{Material and methods \\ APPARATUS}

A VG-Quattro triple quadrupole mass spectrometer (Fisons Instruments, VG-Biotech, Altringham, Cheshire, England) connected to a Carlo-Erba Mega gas chromatograph equipped with an A200S auto sampler (Fisons Instruments, Carlo-Erba, Milan, Italy) was used with a splitless injection technique. The injector temperature was $290^{\circ} \mathrm{C}$, and the starting temperature of the column oven was isothermal at $110^{\circ} \mathrm{C}$ for one minute, then raised at $15^{\circ} \mathrm{C} / \mathrm{min}$ to $280^{\circ} \mathrm{C}$ where it was kept for two minutes. The split exit valve was kept closed for one minute after injection. The temperature of the ion source was $230^{\circ} \mathrm{C}$ and the gas chromatography mass-spectrometry (GC-MS) interface temperature was $280^{\circ} \mathrm{C}$. The capillary inlet pressure of helium was $0.8 \mathrm{~kg} / \mathrm{m}^{3}$. The solvent delay was set to 2.9 minutes. The instrument was used in the chemical ionisation mode with negative ion monitoring and ammonia as the reagent gas. When determining pentafluoropropionic anhydride derivatives of TDA the ions monitored were $\mathrm{m} / \mathrm{z}=394$ and 374 corresponding to the molecular weight (M)-20 and the $M-40$ ions and the $m / z=397$ and 377 ions of the ${ }^{3} \mathrm{H}$ labelled internal standard. The dwell time for each of the ions was $0.2 \mathrm{~s}$ and the interscan delay was $0.02 \mathrm{~s}$. The pressure in the ion source was, in the case of chemical ionisation with ammonia and negative ion monitoring, kept at about $2 \times 10^{-4} \mathrm{mBar}$. The emission current was $200 \mathrm{mV}$ and the electron energy $60 \mathrm{eV}$. The tuning of the instrument was optimised with nonafluorotributylamine as a calibrant.

The high performance liquid chromatographyo (HPLC) equipment consisted of a Waters 6003 multisolvent delivery system (Millipore-Watersse Millford, MA, USA), a Waters 712 WISP with variable injection volume, and a Waters $490 \mathrm{UV}$ detector. For air sampling, SKC model 224-36 pumps (SKC Inc, Eighty Four, Pa, USA) and $30 \mathrm{ml}$ midget impingers containing $10 \mathrm{ml}$ absorption solution were used. Temperature and relative humidity were measured with a Solomat MPM 2000 thermohygrometer (Solomat Corp, Rowayton, USA).

A Sigma 3E-1 centrifuge (Sigma Hartz, Germany) was used for phase separation in the work up procedure. The samples were evaporated in a Speed-Vac 290 centrifuge (Savant, Farmingdale, NY, USA).

\section{COLUMNS}

Fused silica capillary columns $30 \mathrm{~m} \times 0.24 \mathrm{~mm}$ internal diameter with chemically bound stationary phases (DB-5 J and W Scientific, Folsom, CA, USA) with a film thickness of $0.25 \mu \mathrm{m}$ were used for the GC-MS determinations. Columns for HPLC were of stainless steel (200 mm, $5 \mathrm{~mm} \mathrm{ID),}$ packed with $5 \mu \mathrm{m}$ Nucleosil $\mathrm{C}_{18}$ (Macherey-Nagel and Co, Düren, Germany).

\section{CHEMICALS}

2,4-TDA and 2,6-TDA was obtained from Fluka (Buchs, Switzerland); 2,4-TDI and 2,6-TDI (80:20), triethylamine, $\mathrm{HCl}, \mathrm{NaOH}$, and $\mathrm{K}_{2} \mathrm{HPO}_{4}$, 
from E Merck (Darmstadt, Germany); pentafluoropropionic anhydride (PFPA), from Pierce (Rockford, Il, USA); acetonitrile and toluene, from Lab-Scan (Dublin, Ireland); and trideuterated-2,4TDA and 2,6-TDA $\left(\mathrm{CD}_{3} \mathrm{C}_{6} \mathrm{H}_{3}\left(\mathrm{NH}_{2}\right)_{2}\right)$ and 9(N-methylaminomethyl)-anthracene hydrochloride (MAMA) from Synthelec (Lund, Sweden).

\section{PROCEDURE}

\section{Preparation of standard solutions}

Standard solutions of the 2,4-TDA and 2,6-TDA isomers were prepared by dissolving accurately weighed amounts in $0.1 \mathrm{M}$ hydrochloric acid. The solutions were further diluted to the appropriate concentrations.

\section{Sampling and analysis of TDI in air}

For sampling of TDI, we used $30 \mathrm{ml}$ midget impinger flasks containing $10 \mathrm{ml}$ of $1 \times 10^{-4} \mathrm{M}$ amine reagent 9 -(N-methylaminomethyl)-anthracene (MAMA) in toluene. The TDI reacted during sampling with the amine reagent in the impinger flask to form urea derivatives. Different volumes of air were drawn through the absorption reagents at a speed of $11 / \mathrm{min}$. The samples were kept in a refrigerator until analysis. The toluene solution was evaporated to dryness with an evaporation centrifuge. The urea derivatives were dissolved in $1 \mathrm{ml}$ of acetonitrile-water $(70: 30, \mathrm{v} / \mathrm{v})$ and analysed by HPLC with UV detection at $254 \mathrm{~nm}$. The eluent acetonitrile-water was in the ratio $70: 30, \mathrm{v} / \mathrm{v}$, and the water phase contained $3 \%(\mathrm{v} / \mathrm{v})$ triethylamine phosphate (pH 3).

Sampling, handling, and storing of biological samples All urine produced during the study by the nine subjects was collected in polyethylene bottles. The samples were acidified with $5 \mathrm{ml}$ of $6 \mathrm{M} \mathrm{HCl}$ solution per $100 \mathrm{ml}$ of urine and stored in a refrigerator until analysis. The density, creatinine concentration, $\mathrm{pH}$, and total volume of the urine samples were determined.

The urine samples were analysed after acid hydrolysis. Urinary 2,4-TDA and 2,6-TDA excretion was monitored for a $\mathbf{4 8}$ hour period.

Ten $\mathrm{ml}$ venous blood samples were taken on six occasions over a two day period for eight of the subjects and on four occasions for one subject. Plasma was separated within eight hours, transferred to a new tube and kept at $-20^{\circ} \mathrm{C}$ until analysis.

All analyses were done after acid hydrolysis of the plasma samples. The amounts given as 2,4TDA and 2,6-TDA therefore reflect the sum of free and hydrolysable compounds.

Samples of plasma and urine were taken on the first morning before the $\mathbf{4 8}$ hours started, for analysis of the baseline values.

\section{Work up procedure for biological samples}

To a $1 \mathrm{ml}$ urine or plasma sample $1.5 \mathrm{ml}$ of $6 \mathrm{M}$ $\mathrm{HCl}$, containing $\mathrm{D}_{3}$ 2,6-TDA and 2,4-TDA as internal standards each at a concentration of $0.5 \mu \mathrm{g} / 1$ was added. The sample was then hydrolysed at $100^{\circ} \mathrm{C}$ overnight. A $5 \mathrm{ml}$ volume of saturated $\mathrm{NaOH}$ and $2 \mathrm{ml}$ of toluene were added and the mixture was shaken for about 10 minutes and centrifuged at $1500 \mathrm{~g}$ for 10 minutes. A $1.5 \mathrm{ml}$ volume of the organic layer was transferred to a new test tube and $10 \mu \mathrm{l}$ of the anhydride derivatisation reagent was added: The mixture was immediately shaken vigorously for about 10 minutes. The excess of the reagent and acid formed was removed by extraction with $2 \mathrm{ml}$ of $1 \mathrm{M}$ phosphate buffer solution $(\mathrm{pH} 7 \cdot 5)$. A $1 \mathrm{ml}$ volume of the toluene layer containing the amide derivative and the internal standard was transferred to a $1.5 \mathrm{ml}$ auto sampler vial and injected into the GC-MS system. Two aliquots from each sample were worked up and two GC-MS determinations were performed for each aliquot. The average of the four GC-MS measurements was used as an estimate of the concentration.

\section{PROCESS AND EXPOSURE}

The factory produced flexible polyurethane foam in a continuous foam block. The generated foam had a cross section of $1 \mathrm{~m} \times 2 \mathrm{~m}$. The plant used an 80:20 mixture of 2,4-TDI and 2,6-TDI. The TDI monomer, polyol, catalyst, and blowing agents were pumped from tanks and mixed in a foaming nozzle. The material was poured on to moving kraft paper, which passed into a ventilated curing tunnel. The foam had reached its final size within one minute; the paper lining was stripped off and the PUR foam was cut into pieces and moved to a storage room for cooling before further handling. The production was generally based on curing one block in the morning and one block in the afternoon. The TDI foam blocks could be several hundred metres long.

The first day of the study was a Monday. In the morning the workers mainly prepared the machine for the week. In the afternoon a 330 metre block was produced in 75 minutes. The next morning a 90 metre block was produced in about 20 minutes and in afternoon a 180 metre block was produced in 40 minutes. In the first two foam blocks produced, water was used as the blowing agent and carbon dioxide was liberated. In the production of the third block formic acid was used as a blowing agent and carbon monoxide was produced. Both stationary and personal air samples were collected 
at the pouring, paper stripping, and cutting work stations during active production.

\section{SUBJECTS}

Blood and urinary samples for analyses of TDA were taken from seven employees from the plant (mean age 35 (range 24-48) years) and two volunteers $(\mathrm{H}, \mathrm{I}), 40$ and 28 years of age. All were men with the exception of a female laboratory technician $(F)$ working regularly 4.5 hours a day. Of the remaining employees five (A to $\mathrm{E}$ ) were process operators and one the plant manager (G). The work was organised in one eight hour shift a day for five days a week. Subjects $H$ and I were mainly involved in collecting air samples, taking notes, photos etc. They were present in the production area for about $90 \%$ of the study period and also in places where exposure could be expected to be considerable. Only subjects B and E used protective devices (fresh air masks). These were used during the short period of work in the curing tunnel.

\section{HEALTH EXAMINATION}

All nine subjects were interviewed by a physician (LH) for occupational history, smoking habits, and health history. Pulmonary function tests for vital capacity (VC) and forced expiratory volume in one second $\left(\mathrm{FEV}_{1}\right)$ were carried out with a Vitalograph spirometer, both immediately before and immediately after the first work day. A skin prick test with 15 common allergens (Allergologisk Laboratorium, Copenhagen, Denmark) and with a conjugate of TDI and human serum albumin was performed on all subjects. Venous blood samples and urinary samples were taken in the morning. A dipstix test (Labstix) was used for testing for the presence of glucose, albumin, blood, and ketone bodies in urine. Analyses of haemoglobin in blood and white blood cells were performed by routine methods. Antibodies against TDI in plasma were measured with techniques described in detail elsewhere. ${ }^{17}$

\section{Results}

EXPOSURE

The workers regularly wore personal respiratory protection devices only on occasions when high exposure to TDI was expected. During the study, the air concentration of TDI varied greatly. The general TDI concentration around the process machine was $1 \%-10 \%$ of the Swedish TLV. Very high concentrations were found in the tunnel (50 times the TLV). Further exposure to TDI occurred during infrequent work in a TDI tank room and during the filling of a tank from a TDI transportation vehicle. During the study subject A was involved in this work. The TDI used had an isomeric composition of 2,4-TDI and 2,6-TDI in a ratio of $80 \%: 20 \%$. The ratio between 2,4 -TDI and
2,6-TDI varied in the air samples in the range of $60 \%: 40 \%-5 \%: 95 \%$. The air temperature was about $21^{\circ} \mathrm{C}$ and the relative humidity was about $40 \%$. Under normal conditions, dermal exposure to TDI was probably infrequent due to the closed system technique. Dermal exposure to freshly made foam and possibly partly unreacted mixture of TDI and polyol was, however, noted.

\section{HEALTH EXAMINATION}

Two of the process operators $(\mathrm{A}, \mathrm{C})$ and one of the two volunteers (I) were current smokers. Two of the employees wheezed when they had colds, but no work related airway symptoms. Due to an accident in production one of them had been exposed to very high momentary concentrations of TDI 10 years previously. This caused an episode of acute obstructive bronchitis which lasted for several weeks after the accident.

The mean $\mathrm{FEV}_{1}$ for the seven employees as a pércentage of the expected (considering age and height ${ }^{18}$ ) was $104.4 \%$ before the work shift and $105.0 \%$ after the work shift. The corresponding figures for VC were $99.9 \%$ and $100.0 \%$. None of them had any significant decrease in pulmonary function by the end of the shift. None of the employees or the two chemists had any IgE or IgG antibodies against a TDI-HSA conjugate. No abnormalities in haemoglobin, sedimentation rates white blood cell counts, and Labstix test were found, except for a diabetic subject (B) who had slight glucosuria.

\section{PROCEDURE}

\section{Chromatography and mass spectrometry}

The $\mathrm{m} / \mathrm{z}=\mathrm{M}-20$ and the $\mathrm{m} / \mathrm{z}=\mathrm{M}-40$ fragments were monitored by GC-MS. Urine from all nine exposed persons was analysed. For the $m / z=M-$ 20 measurements urine samples from one of the workers showed unresolved separation of the 2,6TDA isomer relative to the matrix. The valley to the baseline between the peaks was about $30 \%$ of the peak height of the 2,6-TDA peak. This resulted in uncertain evaluation of peak areas. When analysing plasma samples the chromatograms were much cleaner and when plasma was analysed from the same worker no interfering peaks were seen. When monitoring the $\mathrm{m} / \mathrm{z}=\mathrm{M}-40$ fragment no interfering peaks were seen for either urine or plasma samples. It is therefore recommended that both the $\mathrm{m} / \mathrm{z}=M-20$ and the $\mathrm{m} / \mathrm{z}=M-40$ fragments be monitored when performing quantitative determinations.

\section{Quantification.}

Coefficients of variation (CVs) defined as $\left(\Sigma(\delta)^{2} \times\right.$ $\left.(2 n)^{-1}\right)^{1 / 2} \times x^{-1}(\delta=$ the difference between the result of two analysed aliquots, $n=$ number of 
samples, $x=$ average of the determinations) were calculated for the TDA measurements. The CV was $6 \%-7 \%$ for both $2,6-$ TDA and 2,4-TDA, at low concentrations of plasma and urine (table 1). At higher concentrations the $\mathrm{CV}$ decreased to lower values. There was a slightly higher $\mathrm{CV}$ for urinary 2,4-TDA. In the procedure two aliquots from each sample were worked up and two GCMS determinations were performed for each aliquot and the average of the four GC-MS measurements was used as an estimate of the concentration. Therefore when performing the actual method, lower CVs than those given in the table would be expected. Calibration plots for human urine spiked with 2,6-and 2,4-TDA in the range of $0 \cdot 2-12 \mu \mathrm{g} / 1$ were produced on eight different occasions over a period of five weeks. The SDs of the calibration plot slopes $(n=8)$ were less than $4 \%$. When the average from the work up procedure of the two aliquots from the same sample differed by more than $40 \%$ the result was disregarded and the procedure was repeated. This was the case in about $5 \%$ of the sample determinations. The overall precision for human urine spiked to a concentration of $1 \mu \mathrm{g} / 1$ was $1.6 \%$ for 2,6 -TDA and $3.5 \%$ for $2,4-$ TDA $(n=10)$.

\section{2,4-TD $A$ and 2,6-TDA in urine}

It was not possible to investigate the individual urinary elimination of TDA relative to the concentration of TDI in the inhalation air. This was due to the limited number of air samples taken $(n=46)$. The average TDI concentration was estimated to be within the range 0.4-4 $\mu \mathrm{g}$ TDI $\mathrm{m}^{3}$. Five of the subjects (A to E) were male workers mainly involved with the TDI foam process. They were considered to get the highest TDI dose during the study. It was not possible to estimate the individual dose in detail. The figure shows that they also had the highest average elimination rate of urinary TDA. The between individual differences in elimination rate of TDA were, however, significant. Two PUR workers (B, C) and two white collar workers $(F, G)$ had similar elimination rate patterns of about 20-70 ng TDA per hour (TDA $=$ the sum of 2,4-TDA and 2,6-TDA). Two subjects (A, D) had an elimination rate of about 100-300 ng TDA per hour. This discrepancy may have been due to different working habits, which we could not identify.

Subject $\mathbf{F}$ was a female laboratory technician mainly working in a separate room and she visited the production area only for very short periods. Subject $\mathrm{G}$ was a supervisor present in the production area about $10 \%$ of the time during the study. They showed the same elimination rate pattern as subjects $\mathrm{B}, \mathrm{C}$, and $\mathrm{E}$. Subjects $\mathrm{F}$ and $\mathrm{G}$ did not use any protective devices during the study, which may explain why they were exposed to TDI.

The two volunteers, subjects $\mathrm{H}$ and $\mathrm{I}$, were present close to the production area and also at places where exposure was expected to be considerable. This explains the high urinary TDA elimination rates during the study.

The elimination rate curves with time (figure) for the workers A to E and the volunteer I showed higher elimination rates during and soon after the TDI foam production. The elimination rates in urine showed a peak about one hour after the TDI foaming in the afternoon of day 2 (about 35 hours). This corresponds to the use of formic acid as the blowing agent. Even subjects $F$ and $G$ who were not present in the production area at that time showed a peak in the elimination rate curves. Their exposure may have been due to some unforeseen problem with, for example, ventilation.

The relation between the 2,4-TDA and 2,6TDA isomers was not constant in the elimination rate curves. The subjects $A$ to $C$ and $G$ showed the same elimination rate of the two isomers. Subject $\mathrm{E}$ showed a more than double elimination rate of 2,6TDA compared with that of 2,4-TDA and subject $F$ showed a more than double elimination rate of 2,4-TDA compared with 2,6-TDA. The relation between the isomers changed with time for subjects $\mathrm{D}, \mathrm{H}$, and I. This may be explained by exposure to different ratios of the TDI isomers in air at different places in the factory.

Urinary TDA was related to density and creatinine over time in essentially the same pattern.

Table 1 Coefficients of variation (CVs) for measurements of TDA

\begin{tabular}{|c|c|c|c|c|}
\hline \multirow[b]{2}{*}{ Concentration of $T D A(\mu g / l)$} & \multicolumn{2}{|l|}{ Plasma } & \multicolumn{2}{|l|}{ Urine } \\
\hline & $\begin{array}{l}2,6-T D A \\
C V(\%)\end{array}$ & $\begin{array}{l}2,4-T D A \\
C V(\%)\end{array}$ & $\begin{array}{l}2,6-T D A \\
C V(\%)\end{array}$ & $\begin{array}{l}2,4-T D A \\
C V(\%)\end{array}$ \\
\hline
\end{tabular}

Each TDA value was calculated from two gas chromatography mass spectrometry measurements. 

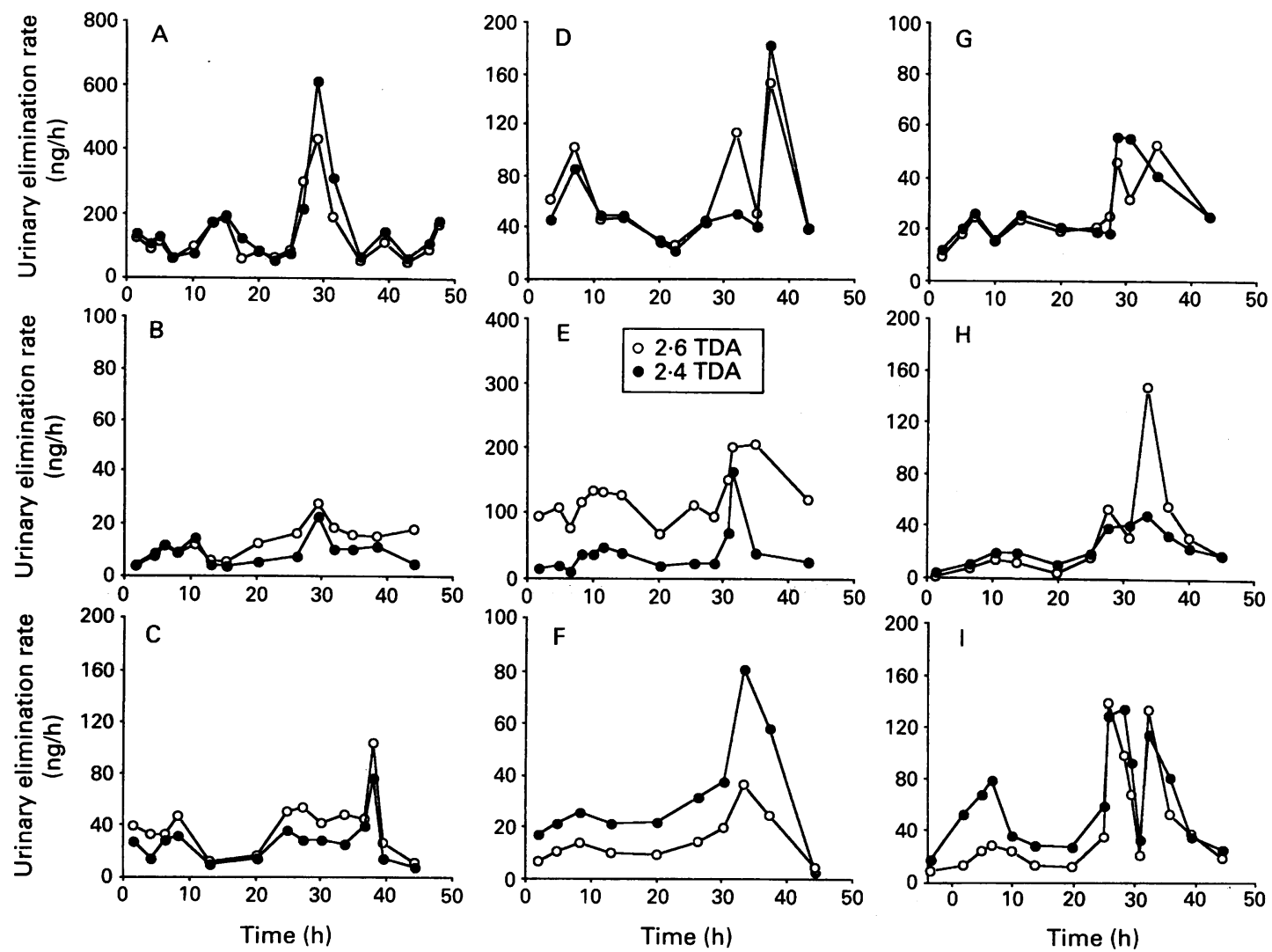

Concentrations of 2,4-TDA and 2-6-TDA (toluenediamine) in hydrolysed urine from workers $A, B, C, D, E$; white collar workers $F, G$, and volunteers $H, I$. Urinary excretion is shown at the midpoint of each observation period. The start time was 0600 on the first morning.

\section{2,4-TDA and 2,6-TDA in plasma}

The concentrations of 2,4-TDA and 2,6-TDA in plasma (table 2) for the subjects A to G were virtually stable. No noticeable correlation between the elimination rate of TDA in urine and plasma concentration of TDA was seen. The subjects A to $E$ showed plasma concentrations of total TDA in the range of $1-8 \mathrm{ng} / \mathrm{ml}$. The laboratory technician (F) had $0 \cdot 2 \mathrm{ng} T \mathrm{TDA} / \mathrm{ml}$ plasma and the supervisor (G) had about $1 \mathrm{ng} \mathrm{TDA} / \mathrm{ml}$ plasma. The volunteers $(\mathrm{H}, \mathrm{I})$ showed an increasing concentration of TDA in plasma with time. At the end of the study the plasma concentrations were $0.6 \mathrm{ng} / \mathrm{ml}$ and 0.2 $\mathrm{ng} / \mathrm{ml}$ plasma.

All subjects showed equal or higher concentrations of the 2,6-TDA isomer compared with the 2,4-TDA isomer. The ratio between the isomers, however, varied. The subjects A, C, D, F, and G had about the same or double the ratio of 2,6-TDA compared with 2,4-TDA. Twelve times higher ratios were found in plasma from subjects $B$ and $E$.
The two volunteers $(\mathrm{H}, \mathrm{I})$ showed increasing concentration of both 2,6-TDA and 2,4-TDA in plasma with time.

\section{Discussion}

To measure the average exposure during a workshift several air samples must be taken as the solvent in the impinger flasks may evaporate to dryness within one hour, depending on the ambient temperature, which makes prolonged sampling complicated. Sampling with the chemosorption technique could have great advantages in these cases but the technique is not yet completely evaluated.

When personal measurements of air sampling exposure are performed to assess the dose, differences between individual subjects in work load affecting the respiratory volume makes the evaluation difficult. One of the greatest disadvantages with air sampling is the necessity to plan the iso- 
Table 2 Concentrations of 2,4-TDA and 2,6-TDA in hydrolysed plasma ( $\mathrm{ng} / \mathrm{ml})$

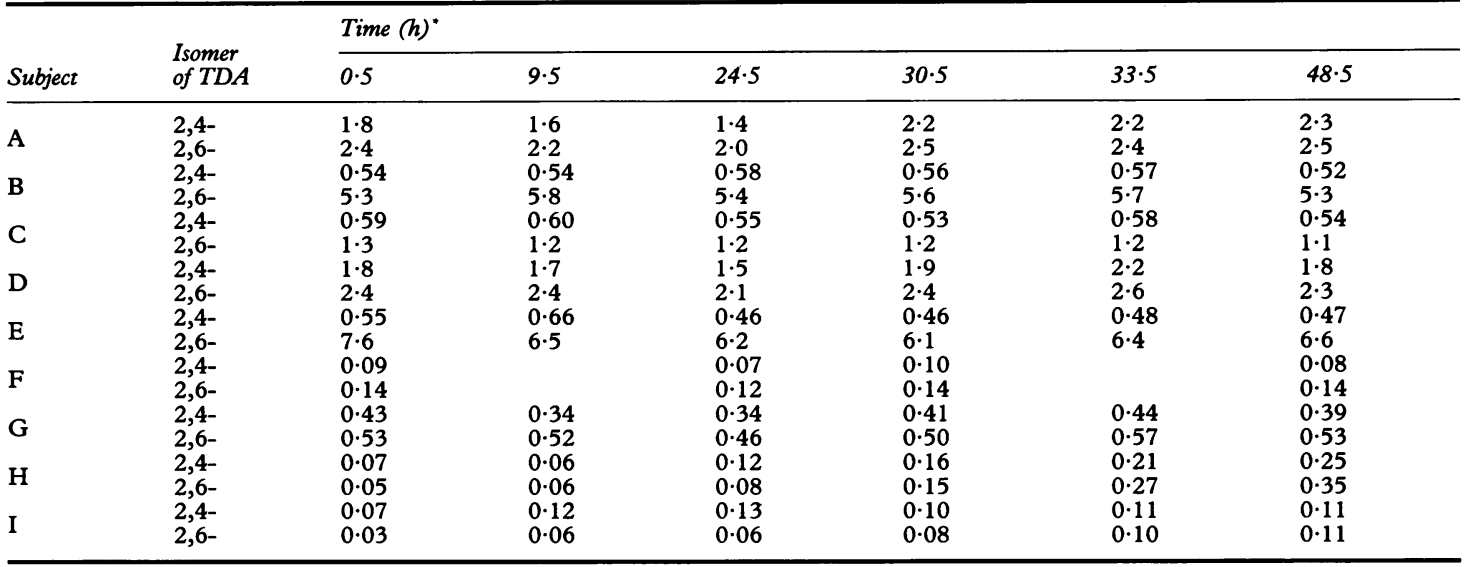

*Start time was 0600 the first day, and the first blood samples (0.5) were taken at 0630 . For details of subjects see figure.

cyanate measurements beforehand and thereby possibly influence the environment at the workplace. Recently a more detailed understanding of isocyanate chemistry in the work environment has been obtained. Workers may not only be exposed to airborne gaseous isocyanate monomers, but also to aerosols containing other compounds necessary for the build up of the polymer. ${ }^{10}$ Furthermore, in an aerosol particle the polymer continues to grow with time and various reaction grades of the isocyanates must be present. Only the isocyanate monomer, however, is determined in air measurements. Theoretically other compounds present in the air and the aerosol particles could influence the uptake of the isocyanate. When exposed to thermal degradation products from a TDI polymer, compounds such as tolueneaminoisocyanates are reported to be present in the air $^{19}$. These types of compounds are not generally measured by the most often used isocyanate methods.

As isocyanates are hazardous, personal protective devices are widely used nowadays. The efficiency of these varies and may also decrease over time if they are handled improperly, as is often the case. Personal exposure measurements are in such situations meaningless. Furthermore, dermal exposure to isocyanates can be expected to happen occasionally even if protective clothes are used. A method for biological monitoring may thus give a more relevant estimate of exposure. Earlier we have reported a GC-MS and electron impact ionisation (EI) method for the determination of TDA in hydrolysed human urine and plasma after exposure to TDI. This method is essentially the same as we have used here. The method ${ }^{20-22}$ (and unpublished data from our laboratory) has been applied to the study of TDA in hydrolysed plasma and urine after controlled exposure of human volunteers at three concentrations in the range of $6-21 \mu \mathrm{g} / \mathrm{m}^{3}$ of 2,4-TDI and $14-50 \mu \mathrm{g} / \mathrm{m}^{3} 2,6-T D I$. In urine the cumulated excreted amount over 24 hours was for 2,4-TDA $15 \%-19 \%$ and for $2,6-$ TDA $17 \%-23 \%$ of the estimated dose. The mean $t_{1 / 2}$ for the concentrations in urine were 1.9 hours for 2,4-TDA and 1.6 hours for 2,6-TDA. There was a linear relation between urinary exeretion and dose found. An association between the dose of TDI and the concentration of TDA in plasma was also noted. The GC-EI method required great care of the mass spectrometer and the detection limit of the method was set by the instrument. The determination of TDA in urine and plasma was made close to the ultimate detection limit. The instrument could only operate in the electron impact and chemical ionisation modes monitoring positive ions, and it gave an acceptable detection limit for only about $10 \%$ of the time. Far better sensitivity and selectivity have been achieved in this study with GC-MS in the chemical ionisation mode with negative ion monitoring and ammonia as the reagent gas. The detection limit achieved was $10 \mathrm{fg}$ for 2,4- and 2,6-TDA injected, corresponding to about $0.01 \mu \mathrm{g} T \mathrm{TDA} / \mathrm{l}$ of human urine or plasma. To estimate exposure to TDI in workers by analysing urine samples the variation of the TDA concentration in urine with time from exposure must be considered. For control of exposure for individual subjects this might be complicated. When estimating exposure for a group this may, however, be a good alternative compared with air measurements. When exposure to TDI was estimated by the monitoring of plasma concentrations of TDA little variation with time after exposure was found. As the plasma concentrations of TDA are stable it is not critical to take the 
blood sample immediately after exposure. Plasma samples can give a measure of long term exposure. The nature of the TDI-protein bonding in humans is not clear at present, but from polyurethane chemistry, it is known that isocyanate bonding to amine and hydroxyl groups is strong with good resistance to hydrolysis. This indicates that more TDI metabolites may be present in the body, which are not determined by the method, based on acid hydrolysis, described in this paper.

As we have reported earlier only about $8 \%-18 \%$ of the inhaled dose of TDI is eliminated in urine. ${ }^{21}$ In another study we found decreasing concentrations of 2,4-TDA and 2,6-TDA in plasma with time $^{22} \quad\left(t_{1 / 2}=\right.$ about 250 hours $)$. How TDI is metabolised in humans is not known in detail. Kennedy et al have described a TDI/TDA plasma protein adduct in rats. In our study the virtually constant plasma concentrations indicate the formation of TDI/TDA plasma protein adducts in humans. In this study it was not possible to analyse the TDA in plasma from workers during a prolonged period free of exposure. It is not feasible to expose volunteers to high doses of TDI necessary for the build up of high plasma concentrations of TDA due to ethical considerations. These matters are presently under study.

It is interesting that the urinary concentrations of the five TDI workers at the beginning of the study were in some cases the same as those of the two volunteers at the end. Taking into consideration the half life of TDA in urine ( $t_{1 / 2}=1.6-1.9$ hours), after TDI exposure several compartments may be involved in the biotransformation of TDI. The relatively high concentration of TDA in urine from the TDI workers may only partly be explained by the degradation of TDI/TDA plasma proteins.

This study indicates that it would be possible to monitor exposure to TDI by monitoring plasma concentrations of TDA. More detailed understanding, however, of the biotransformation of TDI and differences between subjects is necessary.

This work was supported by grants from the Swedish Work Environment Fund and the Medical Faculty, Lund University. We thank Dr Carsten Sangö and Per Brunmark, MSc for valuable help and support and Dr Hans Welinder for performing the RAST and ELISA analyses of TDI antibodies. Valuable help was given by Ms Pia Aprea.

1 World Health Organisation, Environmental health criteria 75, toluene diisocyanates. Geneva: WHO, 1987.

2 Gilbert DS. Fate of TDI and MDI in air, soil, and water. fournal of Cellular Plastics 1988;24:178-92.

3 Wegman DH, Musk W, Main D, Pagnetto CD. Accelerated loss of $\mathrm{FEV}_{1}$ in polyurethane production workers. A fouryear prospective study. Am $\mathcal{F}$ Ind Med 1982;3:209-15.
4 Hagmar L, Nielsen J, Skerfving S. Clinical features and epidemiology of occupational obstructive respiratory disease caused by small molecular weight organic chemicals Monogr Allergy 1987;21:42-58.

5 National Toxicology Program. Toxicology and carcinogenesi studies of commercial grade 2,4(80\%)- and 2,6(20\%)-toluene diisocyanate (CAS No. 26471-62-5) in F344/N rats and B6C3F1 mice (gavage studies). Research Triangle Park, North Carolina: US National Toxicology Program, 1986 Technical Report No 251, NIII Publ No 86-2507.

6 Hagmar L, Welinder H, Mikoczy Z. Cancer incidence and mortality in the Swedish polyurethane foam manufacturing industry. $\mathrm{Br} \mathcal{F}$ Ind Med 1993;50: (in press).

7 Kennedy $\mathrm{AL}$, Brown WE. Isocyanates and lung disease: experimental approaches to molecular mechanisms. Occupational medicine: state of the art review 1992;7:301-29.

8 Sangö C, Zimerson E. A new reagent for determination of isocyanates in working atmospheres by HPLC using UV or fluorescence detection. Fournal of Liquid Chromatography 1980;3:971-90.

9 Skarping G, Smith BEF, Dalene $M$. Trace analysis of amines and isocyanates using glass capillary gas chromatography and selective detection: V. Direct determination of isocyanates using nitrogen-selective and electron-capture detection. $f$ Chromatogr 1985;331:331-8.

10 Lesage J, Goyer N, Desjardins F, Vincent JY, Perrault G Workers' exposure to isocyanates. Am Ind Hyg Assoc 7 1992; 53(2):146-53.

11 Karol MH, Hauth BA, Riley EJ, Magreni CM. Dermal contact with toluene diisocyanate (TDI) produces respiratory tract hypersensitivity in guinea pigs. Toxicol Appl Pharmacol 1981;58:221-30.

12 Ozawa $\mathrm{H}$. Bridging reagent for protein: $\mathrm{I}$. The reaction of diisocyanates with lysine and enzyme proteins. F Biochem 1967;62:419-23.

13 Ted Tse CS, Pesce AJ. Chemical characterisation of isocyanate-protein conjugates. Toxicol Appl Pharmacol 1979;51: $39-46$.

14 Hill BL, Karol $\mathrm{MH}$, Brown WE. The fate of inhaled $\left[{ }^{14} \mathrm{C}\right]$ toluene diisocyanate in sensitized guinea pigs. Toxicologise 1986;6:15.

15 Kennedy AL, Stock ML, Alaire Y, Brown WE. Uptake and distribution of ${ }^{14} \mathrm{C}$ during and following inhalation exposure to radioactive toluene diisocyanate. Toxicol Appl Pharmacol 1989;100:280-92.

16 Rosenberg C, Savolainen H. Determination of occupational exposure to toluene diisocyanate by biological monitoring. $\mathcal{f}$ Chromatogr 1986;367:385-92.

17 Welinder H, Nielsen J, Bensryd I, Skerfving S. IgG antibodies against polyisocyanates in car painters. Clin Allergy 1988;18: 85-93.

18 Berglund E, Birath G, Bjure J, et al. Spiromeric studies in normal subjects: forced spirograms in subjects between 7 and 70 years of age. Acta Med Scand 1963;173:185-92.

19 Skarping G, Renman L, Sangö C, Mathiasson L, Dalene M Capillary gas chromatographic method for the determination of complex mixtures of isocyanates and amines. $\mathcal{F}$ Chromatogr 1985;346:191-204.

20 Sandström JF, Skarping G, Dalene M. Chromatographic determination of amines in biological fluids with special references to the biological monitoring of isocyanates and amines: II. Determination of 2,4- and 2,6-toluenediamine in human urine using capillary gas chromatography and selected ion monitoring with special reference to the biological monitoring of exposure to toluene diisocyanates. f Chromatogr 1989;479:135-43.

21 Brorson T, Skarping G, Sangö C. Biological monitoring of isocyanates and related amines: IV. 2,4- and 2,6-toluenediamine in hydrolysed plasma and urine after test-chamber exposure of humans to 2,4- and 2,6-toluene diisocyanate. Int Arch Environ Health 1991;63:253-9.

22 Skarping G, Brorson T, Sangö C. Biological monitoring of diisocyanates and related amines: III. Test chamber exposure of humans to toluene diisocyanate (TDI). Int Arch Occup Environ Health 1991;63:83-8.

Accepted 10 February 1993 